\title{
The $\mathrm{B}-\mathrm{C}$ and $\mathrm{C}-\mathrm{C}$ bonds as preferred electron source for $\mathrm{H}$-bond and Li-bond interactions in complex pairing of $\mathrm{C} 4 \mathrm{~B} 2 \mathrm{H} 6$ with $\mathrm{HF}$ and LiH molecules
}

\begin{abstract}
Ab}$ initio calculations were used to analyze the interaction of $\mathrm{C} 4 \mathrm{~B} 2 \mathrm{H} 6$ with $\mathrm{HF}$ and $\mathrm{LiH}$ molecules at the mp2/6-311++g $(2 \mathrm{~d}, 2 \mathrm{p})$ computational level. Interaction of C4B2H6 with $\mathrm{HF}$ results to $\mathrm{H}-\mathrm{F} \_\mathrm{H}-\mathrm{C}$ and $\mathrm{C}-\mathrm{B} \_\mathrm{H}-\mathrm{F}, \mathrm{C}-\mathrm{C}_{-}-\mathrm{H}-\mathrm{F}$ hydrogen bond as well as $\mathrm{B}-\mathrm{H} \_\mathrm{H}-\mathrm{F}$ dihydrogen bond complexes. Also interaction of $\mathrm{C} 4 \mathrm{~B} 2 \mathrm{H} 6$ with $\mathrm{LiH}$ results to $\mathrm{B}-\mathrm{C} \_\mathrm{LiH}, \mathrm{C}-$ $\mathrm{C} \_$_ both cases, complexes involving interaction of $\mathrm{HF}$ or $\mathrm{LiH}$ with peripheral $\mathrm{B}-\mathrm{C}$ and $\mathrm{C}-\mathrm{C}$ bonds of the C4B2H6 backbone have greater stabilities. The structures of complexes have been analyzed using AIM and NBO methodologies.
\end{abstract}

Keywords Hydrogen bonding _ Dihydrogen bonding _ Lithium bonding _ Carborane _ C4B2H6

\section{Introduction}

The unique properties of carboranes account for many application in materials science [1-4], nonlinear optics $[2,5,6]$, and medicinal chemistry [1,7-9], especially in boron neutron capture therapy (BNCT). Nido-2,3,4,5-tetracarbahexaborane(6) (Scheme 1) is one of the most carbon-rich carborane systems known [1]. The pentagonal-pyramidal geometry of the nido-2,3,4,5-C4B2 cage is supported by a microwave analysis of parent C4B2H6 [10], a gas-phase electron-diffraction study of Me4C4B2Me2 [11], and X-ray crystallographic and multinuclear NMR investigations of several derivatives. C4B2H6 and its derivatives have been subject of theoretical

studies, molecular and electronic structure calculations, dipole moment, and ionization potential [12-16]. Nido-2,3,4,5-tetracarbahexaborane(6), C4B2H6, exhibits four types of hydrogen atoms, Scheme 1. The H5 and $\mathrm{H} 12$ are two kinds of $\mathrm{H}$ atoms that they have been bonded to the $\mathrm{B}$ atoms (Bd?-d-H bonds), thus known as hydride. On the other hand, H6,9 and H7,8 are two other types of $\mathrm{H}$ atoms which because of their $\mathrm{C}-\mathrm{H}$ bonds they act as protic hydrogens.

An interesting overview of activities of C4B2H6 could be pictured through its intermolecular interactions such asH-bonding, DHB-bonding and Li-bonding. The traditional idea that the hydrogen atoms involved in the HB should be electron-deficient has been overcome with those cases where both interacting atoms were hydrogen, one positively charged and another negatively charged, and this special kind of hydrogen bond has designated as dihydrogen

bond [17-29]. For $\mathrm{C}-\mathrm{H}$ bonds in the C4B2H6, H-bonding with $\mathrm{HX}\left(\mathrm{Hd}+-\mathrm{Xd}-{ }_{-} \mathrm{H}+\mathrm{d}-\mathrm{C}-\mathrm{d}\right)$ or DHB-bonding whit metal hydrides $\left(\mathrm{M}+\mathrm{d}-\mathrm{H}-\mathrm{d} \_\mathrm{H}+\mathrm{d}-\mathrm{C}-\mathrm{d}\right)$ is expected. In contrast, for $\mathrm{B}-\mathrm{H}$ bonds due to bearing negative charge on $\mathrm{H}$ atom DHB-bonding with $\mathrm{HX}(\mathrm{B}$ ? $\mathrm{d}-\mathrm{H}-\mathrm{d}$ $\mathrm{X}-\mathrm{d}$ ) and M-bonding with metal hydrides (B?d-H-d__ M?d-H-d) are expected. Considering extent of applications and importance of carboranes clusters systematic studies on their structures, energies, bonding and other properties is on demand. Here

certifying types and relative strength of interactions which could be occurred between C4B2H6 with $\mathrm{HF}$ and $\mathrm{LiH}$ is aim of this investigation. 


\section{Computational methods}

Calculations were performed using the Gaussian 03 system of codes [30]. The geometries of the isolated C4B2H6, HF and $\mathrm{LiH}$ molecules as well as C4B2H6-HF and C4B2H6- LiH complexes were fully optimized at the $\mathrm{mp} 2 / 6-311+\mathrm{g}(2 \mathrm{~d}, 2 \mathrm{p})$ computational level [31, 32]. Harmonic vibrational frequency calculation confirmed the structures as minimal and enabled the evaluation of zero-point energy (ZPE). The counterpoise procedure was used to correct the interaction energy for basis set superposition error [33]. The AIMAll [34] package was used to obtain bond properties and molecular graphs. The natural bond orbitals (NBO) method implemented within the Gaussian 03 set of codes was applied to perform NBO analysis.

\section{Result and discussion \\ C4B2H6-LiH complexes}

Association of $\mathrm{LiH}$ with $\mathrm{C} 4 \mathrm{~B} 2 \mathrm{H} 6$ led to lithium bond complexes LiB-bc, LiB-5 and LiB-12 as well as DHB-bond complexes DHB-Li-7 and DHB-Li-78, Fig. 1. The LiB and DHB abbreviations were used for showing the Li-bond and DHB-bond interactions, respectively. In the LiB-bc, lithium bond interaction was carried out between the $\mathrm{Li}$ atom and peripheral $\mathrm{B}-\mathrm{C}$ and $\mathrm{C}-\mathrm{C}$ bonds of the C4B2H6 molecule. In this complex, the Li atom has the role of electron acceptor while the peripheral $\mathrm{B}-\mathrm{C}$ and $\mathrm{C}-\mathrm{C}$ bonds of $\mathrm{C} 4 \mathrm{~B} 2 \mathrm{H} 6$ simultaneously play as electron donor. In the LiB-5 and LiB-12 complexes, the $\mathrm{LiH}$ molecule has lithium bonding with $\mathrm{H} 5$ and $\mathrm{H} 12$ atoms (Li___ $\mathrm{H} 5$ and $\mathrm{Li} \_\mathrm{H} 12$ ) of the $\mathrm{C} 4 \mathrm{~B} 2 \mathrm{H} 6$, in which the $\mathrm{B}-\mathrm{H}$ bonds of $\mathrm{C} 4 \mathrm{~B} 2 \mathrm{H} 6$ roles as electron donor and $\mathrm{Li}-\mathrm{H}$ acts as electron acceptor. On the other hand, DHB-Li-7 is a DHB-bond complex which obtained from interaction of $\mathrm{LiH}$ with $\mathrm{H} 7$ atom $\left(\mathrm{H}_{-}\right.$_ H7 $)$of the $\mathrm{C} 4 \mathrm{~B} 2 \mathrm{H} 6$. In this complex, $\mathrm{H}$ atom of $\mathrm{LiH}$ plays as electron donor and $\mathrm{C} 2-\mathrm{H} 7$ bond of $\mathrm{C} 4 \mathrm{~B} 2 \mathrm{H} 6$ acts as

electron acceptor. Eventually, in the $\mathrm{DHB}-\mathrm{Li}-78$, a bifurcate dihydrogen bond interaction was appeared between $\mathrm{H}$ atom of $\mathrm{LiH}$ as electron donor and $\mathrm{H} 7$ and $\mathrm{H} 8$ atoms of C4B2H6 as electron acceptor (H7d?__Hd-___H8d+). Table 1 gives the stabilization energies (SEcorr, corrected with zero-point energies and BSSE) of C4B2H6-HF complexes. Stabilities of C4B2H6-LiH complexes are in the following order, Table 1: LiB-bc[LiB-5[LiB-12[DHB-Li-7 _ DHB-Li-78 Results are showing that Li-bonding between these molecules is stronger than their DHB-bond interactions. Results are showing different tendencies for $\mathrm{B}-\mathrm{H}$ and $\mathrm{C}-\mathrm{H}$ bonds in the $\mathrm{C} 4 \mathrm{~B} 2 \mathrm{H} 6$ for intermolecular interactions. Stabilities of studied complexes are indicating that B10-H5

roles out as a better electron donor than B11-H12 for intermolecular interactions. Apparently, conjugations to peripheral $\mathrm{B}-\mathrm{C}$ bonds make help it in the complex formation with LiH molecule. Thus, LiB-5 is a more stable complex than LiB-12. On the other hand, for the $\mathrm{C}-\mathrm{H}$ bonds labeled as $\mathrm{C} 1-\mathrm{H} 6$ (or $\mathrm{C} 4-\mathrm{H} 9$ ) and $\mathrm{C} 2-\mathrm{H} 7$ (or $\mathrm{C} 3-\mathrm{H} 8$ ), due to greater hydrogen bond donor ability of $\mathrm{C} 2-$ $\mathrm{H} 7(\mathrm{C} 3-\mathrm{H} 8)$, we could only assigned the $\mathrm{Li}+\mathrm{d}-\mathrm{H}-\mathrm{d} \_+\mathrm{dH} 7-\mathrm{C} 2$ (or $\mathrm{Li}+\mathrm{d}-\mathrm{H}-\mathrm{d} \ldots+\mathrm{dH} 8-\mathrm{C} 3$ ) interactions. Initial geometries proposed for $\mathrm{Li}+\mathrm{d}-\mathrm{H}-\mathrm{d} \_+\mathrm{dH} 6-\mathrm{C} 1$ (or $\left.\mathrm{Li}+\mathrm{d}-\mathrm{H}-\mathrm{d} \_+\mathrm{dH} 9-\mathrm{C} 4\right)$ interactions went to $\mathrm{Li}+\mathrm{d}-\mathrm{H}-\mathrm{d} \_+\mathrm{dH} 7-\mathrm{C} 2$ (or $\mathrm{Li}+\mathrm{d}-\mathrm{H}-\mathrm{d} \_+\mathrm{dH} 8-\mathrm{C} 3$ ) structures during optimization. The $\mathrm{Li}-\mathrm{H}$ bond in the free $\mathrm{LiH}$ molecule is $1.604 \mathrm{~A}$ which show 0.026, 0.021, 0.017, 0.001 and $0.002 \mathrm{~A}{ }^{\circ}$ elongations in the LiB-bc, LiB-5, LiB-12, DHB-Li-7 and DHB-Li-78 complexes, respectively, Fig. 1 and Table 2. These variations are showing that more engthening of $\mathrm{Li}-\mathrm{H}$ correspond to complexes with greater stabilities. Also, for Li-bond complexes, a good relationship was seen between interaction energy and elongation of $\mathrm{Li}-\mathrm{H}$ bond. In the $\mathrm{C} 4 \mathrm{~B} 2 \mathrm{H} 6$ part of these complexes, different but smaller bond variations (comparing to the $\mathrm{LiH}$ molecule) could be observed, Table 2 . In the LiB-bc, the Li atom interacts with peripheral $\mathrm{B}-\mathrm{C}$ and $\mathrm{C}-\mathrm{C}$ bonds in the backbone of the C4B2H6. Data given in Table 2 are showing that $\mathrm{B}-\mathrm{B}$ bond has the 
most contraction (-0.019) while $\mathrm{C} 1-\mathrm{B} 10$ and $\mathrm{C} 4-\mathrm{B} 10$ have considerable lengthening (0.006) with complex formation. In the LiB-5, the B-B bond has the greatest shortening (-0.022) while C4B11, B10-H5 and C3-B11 have the most lengthening $(0.011,0.009,0.008)$ with complex formation. Similarly in the LiB-12, greater changes were seen for bonds joined to the B11 atom. So that B11-H12 has the most lengthening in contrast $\mathrm{C} 1-\mathrm{B} 11$ and $\mathrm{C} 2-\mathrm{B} 11$ have the greatest shortening with complex formation. Eventually in the DHB-bond complexes, the C4B2H6 bonds less have been affected by intermolecular

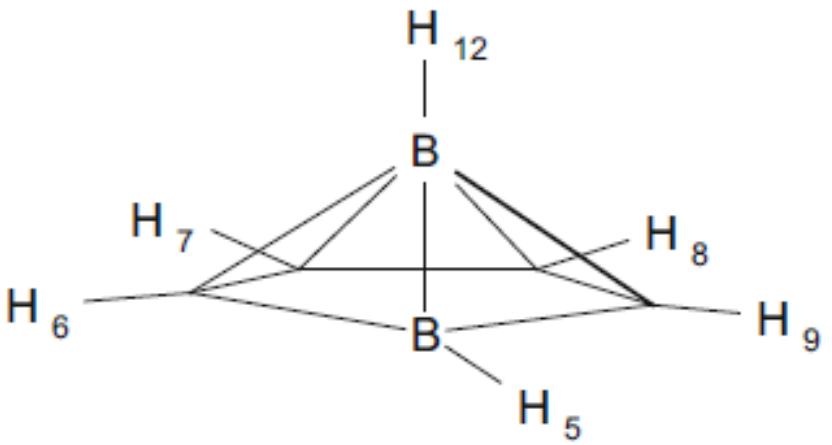

Scheme 1 Schematic representation of C4B2H6 structure interactions, and thus, their changes are smaller than previously mentioned systems. The selected vibrational stretching frequencies ( $\mathrm{cm}-1)$ with corresponding intensities (km mol-1) for complexes are detailed in Table 3 . The $\mathrm{Li}-\mathrm{H}$ bond shows $-73,-58$ and $-49 \mathrm{~cm}-1$ red shift in Li-bond complexes (LiB-bc, LiB-5 and LiB-12), but it show 24 and $21 \mathrm{~cm}-1$ blue shif in DHB-bond systems DHBLi-7 and DHB-Li-78, respectively. These shifts are in agreement with order found for stabilities of complexes. In Li-bond complexes, an efficient agreement was observed between red shift of $\mathrm{Li}-\mathrm{H}$ bond and its bond length variation. For LiB-bc complex, the $\mathrm{C} 1-\mathrm{H} 6$ stretching frequency shows $-10 \mathrm{~cm}-1$ red shift but remaining $\mathrm{C}-\mathrm{H}$ and $\mathrm{B}-\mathrm{H}$ bonds have $11-34 \mathrm{~cm}-1$ blue shift with complex formation. In LiB-5, the B10-H5 and C1-H6 bonds show -67 and $-33 \mathrm{~cm}-1$ red shift while B11-H12 shows $17 \mathrm{~cm}-1$ blue shift and other $\mathrm{C}-\mathrm{H}$ bonds show $4-14 \mathrm{~cm}-$ 1 blue shift with complex formation.

In LiB-12, the $\mathrm{C} 3-\mathrm{H} 8$ and $\mathrm{B} 11-\mathrm{H} 12$ show -30 and $-88 \mathrm{~cm}-1$ red shift but B10-H5 stretching frequency shows $10 \mathrm{~cm}-1$ blue shift with respect to their original bands. For remaining $\mathrm{C}-\mathrm{H}$ bonds, small red shift was observed. Considering the shifts given for Li-bond complexes

(LiB-5 and LiB-12), it might be conclude that the B-H bond involved in the interaction shows red shift while other one shows blue shift with complexation. Also greater shifts were seen for 


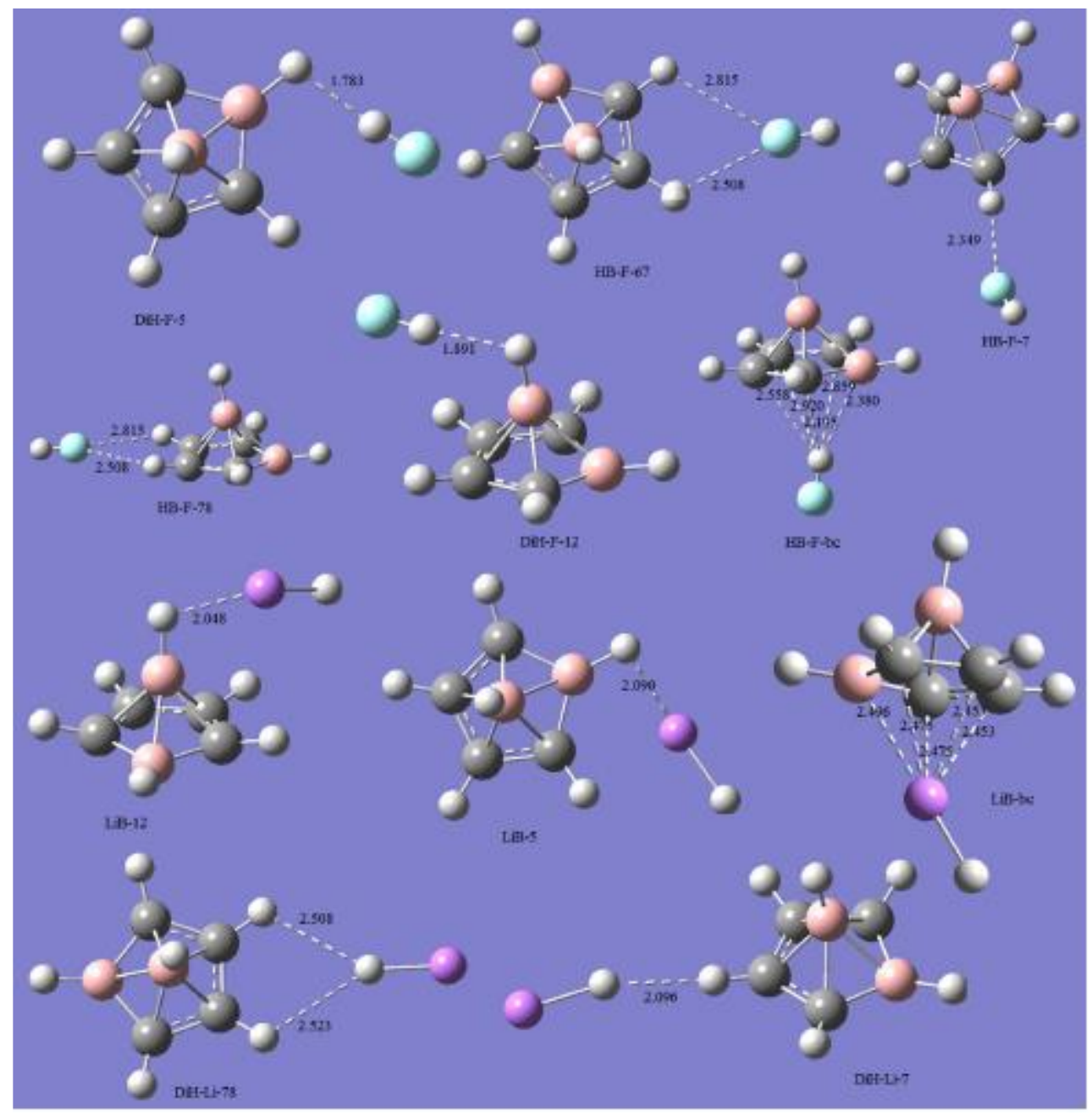

Fig. 1 Schematic representation of C4B2H6 complexes with HF and LiH optimized at MP2/6-311++G(2d,2p) computational level

bonds that have more contributions in intermolecular interactions. In the DHB-Li-7 complex, the C2-H7 and B10-H5 show -70 and -13 red shift, and also for remaining $\mathrm{C}-\mathrm{H}$ bonds smaller amount of red shift ( -2 to $-5 \mathrm{~cm}-1)$ was observed. In the DHB-Li-78, the C1-H6, C2-H7 and B10- H5 show $-25,-25$ and -13 red shift, and also for remaining $\mathrm{C}-\mathrm{H}$ bonds smaller amount of red shift ( -4 to $-5 \mathrm{~cm}-1)$ was observed. Similar to Li-bond complexes in DHB-bond types, greater shifts belong to bonds which are close to interaction position. C4B2H6-HF complexes The 1:1 association of C4B2H6 with HF leads to the formation of DHB-F-5, DHB-F12, HB-F-7, HB-F-78, HB- F-67, and HB-F-bc complexes, Fig. 1.

The DHB-F-5 and DHB-F-12 are two complexes in which DHB-bond interactions have been found between $\mathrm{HF}$ and $\mathrm{B}-\mathrm{H} 5$ and $\mathrm{B}-\mathrm{H} 12$ of $\mathrm{C} 4 \mathrm{~B} 2 \mathrm{H} 6$, respectively. In these complexes, the C4B2H6 behave as HBA and HF as HBD in (B-Hd-___ $\mathrm{d}+\mathrm{H}-\mathrm{F})$ DHB-bonding. The HB-F-7, HBF-78, and $\mathrm{HB}-\mathrm{F} 67$ are $\mathrm{H}$-bond complexes having $\mathrm{H}$-bond interactions between the $\mathrm{C}-\mathrm{H} 7$,

$\mathrm{H} 7,8$, and the $\mathrm{C}-\mathrm{H} 6,7$ (bifurcated H-bonds) of C4B2H6 as HBD with $\mathrm{F}$ atom of $\mathrm{HF}$ as HBA. Finally, in $\mathrm{HB}-\mathrm{F}-\mathrm{bc}$, the $\mathrm{HF}$ molecule has $\mathrm{H}$-bond interaction with peripheral $\mathrm{B}-\mathrm{C}$ and $\mathrm{C}-\mathrm{C}$ bonds of carborane. According to data given in Table 1, stabilities of C4B2H6-HF complexes are in the order: 
HB-F-bc[DHB-F-5[DHB-F-12[HB-F-78[ HB-F-7[HB-F-67

Table 1 The SE uncorr (uncorrected stabilization energies), BSSE, DZPE, and SEcorr (corrected with BSSE and DZPE) in kcal mol-1 calculated at MP2/6-311++G(2d,2p)

\begin{tabular}{lclll}
\hline Complex & SE $^{\text {uncorr }}$ & BSSE & $\Delta$ ZPE & SE $^{\text {cor }}$ \\
\hline HB-F-67 & -1.75 & 0.57 & 0.47 & -0.71 \\
HB-F-7 & -1.74 & 0.53 & 0.42 & -0.79 \\
HB-F-78 & -2.03 & 0.63 & 0.55 & -0.84 \\
DHB-F-12 & -3.29 & 1.00 & 1.23 & -1.06 \\
DHB-F-5 & -4.41 & 1.01 & 1.30 & -2.10 \\
HB-F-bc & -6.23 & 1.63 & 1.43 & -3.17 \\
LiB-bc & -14.73 & 1.83 & 1.47 & -11.43 \\
LiB-5 & -10.45 & 0.97 & 1.26 & -8.22 \\
LiB-12 & -7.46 & 0.91 & 1.13 & -5.42 \\
DHB-Li-7 & -4.30 & 0.39 & 0.74 & -3.17 \\
DHB-Li-78 & -4.30 & 0.38 & 0.73 & -3.19 \\
\hline
\end{tabular}

Values of SEuncorr were determined as follows: SEuncorr $=\mathrm{E}\left(\mathrm{C} 4 \mathrm{~B} 2 \mathrm{H} 6 \_\mathrm{Y}\right)-[\mathrm{E}(\mathrm{C} 4 \mathrm{~B} 2 \mathrm{H} 6)+$ $\mathrm{E}(\mathrm{Y})]$ with $\mathrm{Y}=\mathrm{HF}$ or LiH Values of SEcorr were determined as follows: SEcorr $=$ SEuncorr + DZPE + BSSE Table 2 Bond length (in A ) of C4B2H6-LiH complexes at MP2/6-311++(2d, 2p)

The HF bond is $0.918 \mathrm{~A}^{\circ}$ in the free $\mathrm{HF}$ molecule which shows $0.010,0.005,0.004 \mathrm{~A}^{\circ}$ elongations in the HB-F-bc, DHB-F-12, DHB-F-5 and $0.001 \mathrm{~A}^{\circ}$ in HB-F-78, HB-F-7 and HB-F-67 complexes, respectively, Table 2 . These variations are showing that $\mathrm{HB}-\mathrm{F}-\mathrm{bc}$ with greatest stabilization energies between C4B2H6-HF complexes has more lengthening for HF bond. In rest of C4B2H6-HF complexes, elongation of HF in DHB-bond complexes is greater than simple $\mathrm{H}$-bond ones. Some considerable bond variations could be observed in the carborane part of the C4B2H6-HF complexes, Table 2. 
Table 2 Bond length (in $\mathrm{A}^{\circ}$ ) of C4B2H6-LiH complexes at MP2/6-311??(2d, 2p)

\begin{tabular}{|c|c|c|c|c|c|c|c|c|c|c|c|c|}
\hline Bond & $\begin{array}{l}\mathrm{C}_{4} \mathrm{~B}_{2} \mathrm{H}_{6} \\
r\end{array}$ & $\begin{array}{l}\text { LiB-bc } \\
\Delta r\end{array}$ & LiB-5 & LiB- 12 & $\begin{array}{l}\text { DHB- } \\
\mathrm{Li}-7\end{array}$ & $\begin{array}{l}\text { DHB- } \\
\text { Li-78 }\end{array}$ & $\begin{array}{l}\text { HB- } \\
\text { F-67 }\end{array}$ & $\begin{array}{l}\text { HB- } \\
\text { F-78 } \\
\Delta r\end{array}$ & $\begin{array}{l}\text { HB- } \\
\text { F-7 }\end{array}$ & $\begin{array}{l}\text { DHB- } \\
\text { F-12 }\end{array}$ & $\begin{array}{l}\text { DHB- } \\
\text { F-12 }\end{array}$ & $\begin{array}{l}\text { HB- } \\
\text { F-bc }\end{array}$ \\
\hline C1-H6 & 1.078 & 0 & 0.004 & 0.001 & 0.001 & 0.001 & 0 & 0.001 & 0.001 & 0 & -0.001 & 0 \\
\hline $\mathrm{C} 2-\mathrm{H} 7$ & 1.077 & -0.001 & 0 & 0.001 & 0.005 & 0 & 0 & 0 & 0 & 0.001 & -0.001 & 0 \\
\hline C3-H8 & 1.077 & -0.001 & 0.001 & 0.003 & 0 & 0 & 0 & 0 & 0 & 0.001 & -0.001 & 0 \\
\hline C4-H9 & 1.078 & 0 & 0 & 0.002 & 0.001 & 0.001 & 0.002 & 0.002 & 0.001 & 0 & -0.001 & 0 \\
\hline B10-H5 & 1.183 & -0.004 & 0.009 & -0.001 & 0.002 & 0.002 & 0.001 & 0.001 & 0.001 & -0.001 & 0.006 & -0.002 \\
\hline B11-H12 & 1.173 & -0.001 & -0.001 & 0.011 & 0.002 & 0.002 & 0.001 & 0.001 & 0.001 & 0.006 & -0.001 & 0 \\
\hline B10-B11 & 1.839 & -0.019 & -0.022 & -0.007 & -0.003 & -0.003 & -0.001 & -0.001 & 0 & -0.004 & -0.002 & -0.01 \\
\hline C1-B10 & 1.533 & 0.006 & 0.004 & 0.002 & 0 & 0 & 0 & 0 & -0.001 & 0.001 & -0.005 & 0.006 \\
\hline C1-B11 & 1.717 & -0.001 & -0.002 & -0.016 & -0.003 & -0.002 & -0.001 & -0.001 & -0.002 & -0.006 & 0.004 & -0.005 \\
\hline $\mathrm{C} 1-\mathrm{C} 2$ & 1.442 & 0.004 & -0.001 & 0.005 & 0.001 & 0.001 & 0 & 0.001 & 0.001 & 0.001 & -0.001 & 0.004 \\
\hline $\mathrm{C} 2-\mathrm{C} 3$ & 1.426 & 0.001 & -0.001 & 0 & 0 & -0.002 & 0 & -0.001 & 0 & 0.002 & -0.002 & -0.001 \\
\hline C2-B11 & 1.718 & 0.001 & 0.006 & -0.012 & 0.001 & -0.002 & -0.001 & -0.001 & 0 & -0.004 & 0.002 & -0.002 \\
\hline $\mathrm{C} 3-\mathrm{C} 4$ & 1.442 & 0.004 & -0.003 & 0.004 & 0.002 & 0.002 & 0.001 & 0.001 & 0.001 & 0.001 & -0.001 & -0.001 \\
\hline C3-B11 & 1.718 & -0.002 & 0.008 & -0.002 & -0.004 & -0.002 & -0.001 & -0.001 & -0.002 & -0.003 & 0.002 & 0.004 \\
\hline C4-B10 & 1.533 & 0.006 & -0.01 & 0.003 & -0.001 & 0 & 0 & 0 & 0 & 0.001 & -0.003 & -0.001 \\
\hline C4-B11 & 1.717 & -0.001 & 0.011 & -0.009 & -0.001 & -0.002 & 0 & -0.001 & -0.001 & -0.006 & 0.004 & 0.002 \\
\hline $\mathrm{Li}-\mathrm{H}$ & 1.604 & 0.026 & 0.021 & 0.017 & 0.001 & 0.002 & 0.001 & 0.001 & 0.001 & 0.005 & 0.004 & 0.01 \\
\hline
\end{tabular}

For HB-F-bc, data given in Table 2 are showing that $\mathrm{B}-\mathrm{B}$ bond has the most contraction $(-0.010)$ while $\mathrm{C} 1-\mathrm{B} 10$ has considerable elongations (0.006) with complex formation. These variations are implying that those parts of C4B2H6 which have smaller intermolecular distances $(2.195$ and 2.380 for $\mathrm{H} 13$ _ $\mathrm{C} 1$ and $\mathrm{H} 13 \ldots$ B 10 ) have greater changes. In the $\mathrm{DHB}-\mathrm{F}-5$, the $\mathrm{C} 1-\mathrm{B} 10$ bond has the greatest shortening (-0.005) while B10-H5 has the most lengthening (0.006) with complex formation. Similarly in the DHB-F-12, greater changes were seen for bonds joined to the B11 atom. So that B11-H12 has the most lengthening, in contrast C1-B11 and C4-B11 have the greatest shortening among its bonds. Eventually in the H-bond complexes HB-F-78, HB-F-7 and $\mathrm{HB}-\mathrm{F}-67$, the C4B2H6 bonds less have been affected by intermolecular interactions; thus, their changes are smaller than previously mentioned systems $(0.001-0.002)$. These results are showing that bond variations are in line with relative stabilities of complexes. The selected vibrational stretching frequencies (cm-1) with corresponding intensities (km mol-1) for HF and C4B2H6 free molecule as well as their complexes are listed in Table 4.

In the C4B2H6-HF complexes, the $\mathrm{H}-\mathrm{F}$ bands show red shift upon complex formation. These red shifts are $-219,-127,-108,-18,-17$, and -15 for HB-F-bc, DHB- F-12, DHB-F-5, HB-F-7, HBF-78, and HB-F-67, respectively.

These results are showing that red shift of HF band in the DHB-bond complexes is greater than simple H-bond complexes (HB-F7, HB-F-78, and HB-F67). Apparently, due to rB-H to r*H-F charge transfer, interactions in which $\mathrm{HF}$ acts as HBD have greater red shift than interaction with HF as HBA. For the B10-H5 bond we have-5 cm-1 red shift in HB-F -7 and HB-F-67 complexes; also this bond has $-49 \mathrm{~cm}-1$ red shift in DHB-F-5. But in HB-F-78,DHB-F-12 and HB-F-bc it show 4, 8 and $15 \mathrm{~cm}-1$ blue shift, respectively. Similarly for B11-H12 stretching frequencies -43 red shift in DHB-F-12, 14 and $9 \mathrm{~cm}-1$ blue shift inDHB-F-5 andHB-F-bc were seen. Results of this study is dialing with the presence of multisites on the C4B2H6 backbone which could act as Lewis acid or Lewis base for intermolecular interactions. According to above 
discussions for both C4B2H6-HF and C4B2H6- $\mathrm{LiH}$ systems, the peripheral $\mathrm{B}-\mathrm{C}$ and $\mathrm{C}-\mathrm{C}$ bonds as electron donor have strongest interaction with target molecules as electron acceptors. Therefore, from different models which have been considered for interaction of $\mathrm{C} 4 \mathrm{~B} 2 \mathrm{H} 6$ with $\mathrm{HF}$ and $\mathrm{LiH}$ molecules, complexes involving peripheral $\mathrm{B}-\mathrm{C}$ and $\mathrm{C}-\mathrm{C}$ bonds as electron donor have the greatest stabilities. Comparing results of current study with our last work [27] (CB4H8-HF complexes) is showing that interaction of $\mathrm{HF}$ with $\mathrm{B}-\mathrm{B}$ bond in the $\mathrm{CB} 4 \mathrm{H} 8$ is stronger than its interactions with $\mathrm{B}-\mathrm{C}$ bonds in the $\mathrm{C} 4 \mathrm{~B} 2 \mathrm{H} 6$ molecule. Also $\mathrm{HB}(\mathrm{H}-\mathrm{F}-\mathrm{H}-\mathrm{C})$ and $\mathrm{DHB}(\mathrm{B}-$ $\mathrm{H} \_\mathrm{H}-\mathrm{F}$ ) interactions of $\mathrm{HF}$ with $\mathrm{CB} 4 \mathrm{H} 8$ are close to similar interactions between $\mathrm{HF}$ and C4B2H6. Both studies are dealing with stronger interactions for $\mathrm{HF}$ with $\mathrm{B}-\mathrm{B}$ and $\mathrm{B}-\mathrm{C}$ bonds relative to $\mathrm{H}-\mathrm{F} \_$_ $\mathrm{H}-\mathrm{C}$ and $\mathrm{B}-\mathrm{H} \mathrm{H}_{2} \mathrm{H}_{-}-\mathrm{F}$ interactions in both carborane molecules.

Table 3 Unscaled vibrational frequencies (cm-1) with corresponding intensities (values given in parenthesis, $\mathrm{km}$ mol-1) for C4B2H6-Hli Complexes

\begin{tabular}{|c|c|c|c|c|c|c|c|c|c|c|c|}
\hline & \multirow{2}{*}{$\begin{array}{l}\mathrm{C}_{4} \mathrm{~B}_{2} \mathrm{H}_{6} \\
v\end{array}$} & \multicolumn{2}{|l|}{ LiB-5 } & \multicolumn{2}{|l|}{ LiB-12 } & \multicolumn{2}{|l|}{ DHB-Li-7 } & \multicolumn{2}{|c|}{ DHB-Li-78 } & \multicolumn{2}{|l|}{ LiB-bc } \\
\hline & & $v$ & $\Delta v$ & $v$ & $\Delta v$ & $v$ & $\Delta v$ & & & $v$ & $\Delta v$ \\
\hline $\mathrm{C} 1-\mathrm{H} 6$ & $3246(0)$ & 3213 (6) & -33 & $3247(0)$ & 1 & 3244 (3) & -2 & 3242 & -25 & $3257(0)$ & -10 \\
\hline $\mathrm{C} 2-\mathrm{H} 7$ & $3267(0)$ & 3271 (1) & 4 & 3263 (1) & -4 & 3197 (110) & -70 & 3242 & -25 & $3283(5)^{\mathrm{a}}$ & 16 \\
\hline $\mathrm{C} 3-\mathrm{H} 8$ & $3267(0)$ & $3261(1)$ & 4 & 3237 (7) & -30 & $3260(1)$ & -7 & 3242 & -4 & $3274(6)^{\mathrm{b}}$ & 28 \\
\hline C4-H9 & $3246(0)$ & 3251 (1) & 14 & 3237 (7) & -9 & $3242(1)$ & -4 & 2781 & -5 & $3257(0)$ & 22 \\
\hline B10-H5 & $2712(105)$ & $2645(100)$ & -67 & $2722(87)$ & 10 & 2699 (126) & -13 & 2699 & -13 & $2746(66)$ & 34 \\
\hline B11-H12 & $2786(45)$ & $2803(30)$ & 17 & $2698(104)$ & -88 & $2781(50)$ & -5 & 3242 & -4 & $2808(31)$ & 11 \\
\hline$X \cdots Y$ & - & 247 (37) & - & 209 (165) & - & $101(78)$ & - & 1439 & 21 & 267 (18) & - \\
\hline $\mathrm{H}-\mathrm{Li}$ & 1418 (229) & $1361(389)$ & -58 & $1370(318)$ & -49 & $1442(349)$ & 24 & & & $1343(440)$ & -75 \\
\hline
\end{tabular}

\section{AIM analysis}

The atoms in molecules (AIM) theory [34] are applied here to analyze the characteristics of the

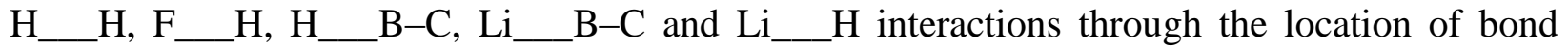
critical points $(\mathrm{BCP})$ with $(3,-1)$ coordinates in the Hessian matrix fitted to the intermolecular contact area. The parameters electronic density (q), Laplacian (r2q), and the ratios between the kinetic $(\mathrm{G})$ and potential (U) electron energy density [35] derived from the Bader theory could indicate the type of interaction. The atomic connection is recognized as close-shell interaction, which is often designated to H-bonds or other intermolecular weakly bound contacts, such as halogen bonds, dihydrogen bonds, and p-staking [36-42]. The analysis of the electron density within the AIM methodology shows the presence of bond critical points (Table 5) between the atoms involved in the interactions. All kinds of $\mathrm{H}_{-} \mathrm{H}_{2} \mathrm{H}_{-} \mathrm{F}, \mathrm{H}_{-} \mathrm{B}_{-} \mathrm{C}, \mathrm{Li}_{-} \mathrm{B}_{-} \mathrm{C}$, and $\mathrm{Li} \_\mathrm{H}$ interactions have rqBCP $2[0$ and $-\mathrm{GC} / \mathrm{VC}[1$ which might consider as interactions with noncovalent character. 
Table 5 Topological parameters for the fully optimized complexes

\begin{tabular}{lllll}
\hline Complex & H-bond & $\rho_{\mathrm{BCP}}$ & $\nabla_{\rho \mathrm{BCP}}^{2}$ & $-\mathrm{Gc} / \mathrm{Vc}$ \\
\hline LiB-5 & $\mathrm{Li} \cdots \mathrm{H} 5$ & 0.0122 & 0.0649 & 1.2177 \\
LiB-12 & $\mathrm{Li} \cdots \mathrm{H} 12$ & 0.0108 & 0.0587 & 1.2641 \\
DHB-Li-7 & $\mathrm{H} 14 \cdots \mathrm{H} 7$ & 0.0113 & 0.0246 & 1.06 \\
DHB-Li-78 & $\mathrm{H} 14 \cdots \mathrm{H} 7$ & 0.0062 & 0.0158 & 1.2115 \\
& $\mathrm{H} 14 \cdots \mathrm{H} 8$ & 0.006 & 0.0156 & 1.2168 \\
LiB-bc & $\mathrm{Li} \cdots \mathrm{B}-\mathrm{C}$ & 0.0125 & 0.0665 & 1.218 \\
HB-F-67 & $\mathrm{F} 13 \cdots \mathrm{H} 6$ & 0.0039 & 0.018 & 1.3066 \\
& $\mathrm{~F} 13 \cdots \mathrm{H} 7$ & 0.0064 & 0.0284 & 1.2116 \\
HB-F-7 & $\mathrm{F} 14 \cdots \mathrm{H} 7$ & 0.0082 & 0.0343 & 1.1605 \\
HB-F-78 & $\mathrm{F} 13 \cdots \mathrm{H} 7$ & 0.0054 & 0.0241 & 1.2401 \\
& $\mathrm{~F} 13 \cdots \mathrm{H} 8$ & 0.0056 & 0.0246 & 1.2349 \\
DHB-F-12 & $\mathrm{H} 13 \cdots \mathrm{H} 12$ & 0.0144 & 0.0399 & 1.0536 \\
DHB-F-5 & $\mathrm{H} 13 \cdots \mathrm{H} 5$ & 0.0165 & 0.0453 & 1.0217 \\
HB-F-bc & $\mathrm{H} \cdots \mathrm{B}-\mathrm{C}$ & 0.0184 & 0.049 & 1.0236 \\
\hline
\end{tabular}

Natural bond orbital analysis Natural bond orbital (NBO) analysis [43] was performed for the minima found on the studied $\mathrm{LiH}-\mathrm{C} 4 \mathrm{~B} 2 \mathrm{H} 6$ and $\mathrm{HF}-\mathrm{C} 4 \mathrm{~B} 2 \mathrm{H} 6$ complexes. These complex formations are associated with orbital interactions between the bonding pairs in the electron donor and the antibonding orbital in the electron acceptor. The quantity of charge transferred from donor to the acceptor (DQ) due to the interaction of donor and acceptor orbitals is $0.0762,0.0366,0.0256$, 0.0092, and 0.0032 for LiB-bc, LiB-5, LiB-12, DHB-Li-7, and DHB- 78 as well as 0.0019, 0.0019.0020, 0.0022, 0.0024, and 0.0045 for HB-F-7, HB-F-67, HB-F-78, DHB-F-5, DHB-F12, and HB-F-bc, respectively. Data given in Table 6 are illustrating sets of charge transfers between $\mathrm{HF}$ and $\mathrm{LiH}$ with $\mathrm{C} 4 \mathrm{~B} 2 \mathrm{H} 6$ in each of the studied complexes. From these sets, charge transfers having grater binding energies might be considered as preferred part of interaction during complex formation. For example in LiB-bc complex, the $\mathrm{rC} 1-\mathrm{B} 10+\mathrm{r}^{*} \mathrm{Li13}-$ $\mathrm{H} 14$, and $\mathrm{rC} 4-\mathrm{B} 10+\mathrm{r}^{*} \mathrm{Li} 13-\mathrm{H} 14$ acts as stronger parts of interactions. Also in DHB-F-12, the rB11-H12 + r*H13-F14 is more important than other charge transfers. Conclusions C4B2H6 could have intermolecular interactions with $\mathrm{HF}$ and $\mathrm{LiH}$ molecules. For interaction of C4B2H6 with HF, H-bond, and DHB-bond and for $\mathrm{LiH}$, Li-bond, and DHB-bond, complexes have been obtained. According to our results, C4B2H6- LiH dimers are more stable than C4B2H6-HF, and this returns to the greater dipole moment of $\mathrm{LiH}$ with respect to HF. Also from different models of interactions, complexes involving pripheral $\mathrm{B}-\mathrm{C}$ and $\mathrm{C}-\mathrm{C}$ bonds as electron donor have greatest stabilities in both systems. 
Table 6 NBO parameters for the optimized complexes 


\begin{tabular}{|c|c|c|c|c|}
\hline Complex & QCT & Charge transfer & & $E^{(2)}$ \\
\hline \multirow[t]{3}{*}{ DHB-F-5 } & 0.00224 & $\sigma \mathrm{C} 1-\mathrm{B} 11$ & *H13-F14 & 0.15 \\
\hline & & $\sigma \mathrm{C} 4-\mathrm{B} 11$ & ${ }^{*} \mathrm{H} 13-\mathrm{F} 14$ & 0.26 \\
\hline & & $\sigma \mathrm{H} 5-\mathrm{B} 10$ & ${ }^{*} \mathrm{H} 13-\mathrm{F} 14$ & 4.20 \\
\hline HB-F-7 & 0.00193 & LP F14 & $* \mathrm{C} 2-\mathrm{H} 7$ & 1.49 \\
\hline \multirow[t]{3}{*}{ HB-F-bc } & 0.00446 & $\sigma \mathrm{C} 1-\mathrm{B} 10$ & ${ }^{*} \mathrm{H} 13-\mathrm{F} 14$ & 1.92 \\
\hline & & $\sigma \mathrm{C} 1-\mathrm{B} 11$ & ${ }^{*} \mathrm{H} 13-\mathrm{F} 14$ & 2.54 \\
\hline & & $\sigma \mathrm{B} 11-\mathrm{H} 12$ & ${ }^{*} \mathrm{H} 13-\mathrm{F} 14$ & 0.22 \\
\hline \multirow[t]{6}{*}{ DHB-F-12 } & 0.00235 & $\sigma \mathrm{C} 1-\mathrm{B} 10$ & ${ }^{*} \mathrm{H} 13-\mathrm{F} 14$ & 0.19 \\
\hline & & $\sigma \mathrm{C} 1-\mathrm{B} 11$ & *H13-F14 & 0.58 \\
\hline & & $\sigma \mathrm{C} 2-\mathrm{C} 3$ & *H13-F14 & 0.49 \\
\hline & & $\sigma \mathrm{C} 4-\mathrm{B} 10$ & $*$ H13-F14 & 0.18 \\
\hline & & $\sigma \mathrm{C} 4-\mathrm{B} 11$ & ${ }^{*} \mathrm{H} 13-\mathrm{F} 14$ & 0.50 \\
\hline & & $\sigma \mathrm{B} 11-\mathrm{H} 12$ & ${ }^{*} \mathrm{H} 13-\mathrm{F} 14$ & 2.00 \\
\hline HB-F-67 & 0.00186 & lp F13 & $* \mathrm{C} 2-\mathrm{H} 7$ & 0.30 \\
\hline \multirow[t]{2}{*}{ HB-F-78 } & 0.00200 & lp F13 & ${ }^{*} \mathrm{C} 2-\mathrm{H} 7$ & 0.12 \\
\hline & & lp F13 & $* \mathrm{C} 3-\mathrm{H} 8$ & 0.13 \\
\hline \multirow[t]{7}{*}{ Li B-12 } & 0.02556 & $\sigma \mathrm{C} 1-\mathrm{C} 2$ & *Li13-H14 & 0.64 \\
\hline & & $\sigma \mathrm{C} 1-\mathrm{B} 10$ & *Li13-H14 & 0.78 \\
\hline & & $\sigma \mathrm{C} 2-\mathrm{C} 3$ & *Li13-H14 & 0.73 \\
\hline & & $\sigma \mathrm{C} 3-\mathrm{C} 4$ & *Li13-H14 & 0.20 \\
\hline & & $\sigma \mathrm{C} 3-\mathrm{H} 8$ & *Li13-H14 & 0.68 \\
\hline & & $\sigma \mathrm{C} 4-\mathrm{H} 9$ & *Li13-H14 & 1.16 \\
\hline & & $\sigma \mathrm{C} 4-\mathrm{B} 10$ & *Li13-H14 & 0.79 \\
\hline \multirow[t]{10}{*}{ LiB-5 } & 0.03664 & $\sigma \mathrm{C} 1-\mathrm{C} 2$ & *Li13-H14 & 2.81 \\
\hline & & $\sigma \mathrm{C} 1-\mathrm{H} 6$ & *Li13-H14 & 3.27 \\
\hline & & $\sigma \mathrm{C} 1-\mathrm{B} 10$ & *Li13-H14 & 9.68 \\
\hline & & $\sigma \mathrm{C} 1-\mathrm{B} 11$ & *Li13-H14 & 1.56 \\
\hline & & $\sigma \mathrm{C} 2-\mathrm{C} 3$ & *Li13-H14 & 0.45 \\
\hline & & $\sigma \mathrm{C} 3-\mathrm{C} 4$ & *Li13-H14 & 0.11 \\
\hline & & $\sigma \mathrm{C} 4-\mathrm{B} 10$ & *Li13-H14 & 3.36 \\
\hline & & $\sigma \mathrm{C} 4-\mathrm{B} 11$ & *Li13-H14 & 2.50 \\
\hline & & $\sigma \mathrm{H} 5-\mathrm{B} 10$ & *Li13-H14 & 13.18 \\
\hline & & $\sigma \mathrm{B} 11-\mathrm{H} 12$ & *Li13-H14 & 0.19 \\
\hline \multirow[t]{13}{*}{ LiB-bc } & 0.07547 & $\sigma \mathrm{C} 1-\mathrm{C} 2$ & *Li13-H14 & 9.03 \\
\hline & & $\sigma \mathrm{C} 1-\mathrm{H} 6$ & *Li13-H14 & 1.87 \\
\hline & & $\sigma \mathrm{C} 1-\mathrm{B} 10$ & ${ }^{*} \mathrm{Li} 13-\mathrm{H} 14$ & 16.12 \\
\hline & & $\sigma \mathrm{C} 1-\mathrm{B} 11$ & *Li13-H14 & 3.22 \\
\hline & & $\sigma \mathrm{C} 2-\mathrm{C} 3$ & *Li13-H14 & 11.06 \\
\hline & & $\sigma \mathrm{C} 2-\mathrm{H} 7$ & *Li13-H14 & 2.78 \\
\hline & & $\sigma \mathrm{C} 3-\mathrm{C} 4$ & *Li13-H14 & 9.01 \\
\hline & & $\sigma \mathrm{C} 3-\mathrm{H} 8$ & *Li13-H14 & 2.78 \\
\hline & & $\sigma \mathrm{C} 4-\mathrm{H} 9$ & *Li13-H14 & 1.87 \\
\hline & & $\sigma \mathrm{C} 4-\mathrm{B} 10$ & *Li13-H14 & 16.09 \\
\hline & & $\sigma \mathrm{C} 4-\mathrm{B} 11$ & *Li13-H14 & 3.23 \\
\hline & & $\sigma \mathrm{H} 5-\mathrm{B} 10$ & *Li13-H14 & 4.18 \\
\hline & & $\sigma \mathrm{B} 11-\mathrm{H} 12$ & *Li13-H14 & 1.72 \\
\hline DHB-Li-7 & 0.00915 & $\sigma \mathrm{Li13}-\mathrm{H} 14$ & $* \mathrm{C} 2-\mathrm{H} 7$ & 8.07 \\
\hline
\end{tabular}




\section{References}

1. Grimes Russell N (2011) Carboranes, 2nd edn. Academic Press, London

2. Hosmane NS (2011) Boron science: new technologies and applications. Taylor \& Francis Books/CRC Press, Boca Raton 3. Spokoyny AM, Farha OK, Mulfort KL, Hupp JT, Mirkin CA (2010) Porosity tuning of carborane-based metal-organic frameworks (MOFs) via coordination chemistry and ligand design. Inorg Chim Acta 364:266-271

3. Spokoyny AM, Farha OK, Mulfort KL, Hupp JT, Mirkin CA (2010) Porosity tuning of carborane-based metalorganic frameworks (MOFs) via coordination chemistry and ligand design. Inorg Chim Acta 364:266-271.

4. Eo M, Park MH, Kim T, Do Y, Lee MH (2013) Polynorbornene copolymers with pendent ocarborane and carbazole groups: novel side-chain donor-acceptor copolymers for turn-on sensing of nucleophilic anions. Polymer 54:6321-6328.

5. Zou HY, Ma NN, Sun SL, Li X, Qiu YQ (2013) Structures and redox-switchable second-order nonlinear optics properties of N-legged piano stool shaped 12-vertex rhenacarborane halfsandwich complexes. J Organomet Chem 728:6-15.

6. Liu Y, Yang G, Sun S, Su Z (2012) Theoretical investigation on two-dimensional moleculebased second-order nonlinear optical materials of the disubstituted o-carborane derivatives. Comput Theor Chem 992:142-149

7. Valliant JF, Guenther KJ, King AS, Morel P, Schaffer P, Sogbein OO, Stephenson KA (2002) The medicinal chemistry of carboranes. Coord Chem Rev 232:173-230

8. Calabrese G, Nesnas JJ, Barbu E, Fatouros D, Tsibouklis J (2012) The formulation of polyhedral boranes for the boron neutron capture therapy of cancer. Drug Discovery Today 17:153-159

9. Białek-Pietras M, Olejniczak AB, Tachikawa S, Nakamura H, Les'́ - nikowski ZJ (2013) towards new boron carriers for boron neutron capture therapy, Metallacarboranes bearing cobalt, iron and chromium and their cholesterol conjugates. Bioorg Med Chem 21:1136-1142

10. Pasinski JP, Beaudet RA (1974) Microwave spectrum, structure, and dipole moment of 2,3,4,5tetracarbahexaborane(6). J Chem Phys 61:683

11. Haase J (1973) The Molecular Structure of Hexamethyl-tetracarbahexaborane(6). Z. Naturforsch. A 28:785

12. Dewar MJS, Jie C, Zoebisch EG (1988) AM1 calculations for compounds containing boron. Organometallics 7:513

13. Epstein IR, Tossell JA, Switkes E, Stevens RM, Lipscomb WN (1971)Hexaborane (10): self consistent fieldwavefunction, localized orbitals and relationships to chemical properties. Inorg Chem 10:171

14. Tian SX (2005) Theoretical study of isoelectronic molecules: B6H10, 2-CB5H9, 2,3-C2B4H8, 2,3,4-C3B3H7, and 2,3,4,5- C4B2H6. J Phys Chem A 109:6580

15. Gill WR, Jones ME, Wade K, Porterfield WW, Wong EH (1992) Stability patterns in borane cluster chemistry rationalized by extended Hu“ckel molecular orbital studies. J. Mol. Struct.

(Theochem) 261:161

16. Hofmann M, Fox MA, Greatrex R, Schleyer PVR, Williams RE (2001) Empirical and ab initio energy/architectural patterns for 73 nido-6 IV [-carborane isomers, from $\mathrm{B}(6) \mathrm{H}(9)(-)$ to

C(4)B(2)H(6). Inorg Chem 40:1790 
17. Alkorta I, Rozas I, Elguero J (1998) Non-conventional hydrogen bonds. J. Chem. Soc. Rev. 27:163

18. Desiraju GR, Steiner T (1999) The weak hydrogen bond. Oxford University Press, Oxford 19. Nie Y, Miao J, Pritzkow H, Wadepohl H, Siebert W (2013) Weak intramolecular C-H__H$\mathrm{B}$ and $\mathrm{C}-\mathrm{H} \_\mathrm{Cl}$ interactions in C-aminoboryl-o-carboranes. J Organomet Chem 747:174-177 20. Kononova EG (2013) Electronic structure of 10-vertex arachno- borane and-carborane clusters. Comput Theor Chem 1026:17-23

21. Solimannejad M, Amlashi LM, Alkorta I, Elguero J (2006) XeH2 as a proton-accepting molecule for dihydrogen bonded systems: a theoretical study. J Chem Phys Lett 422:226

22. Alkorta I, Zborowski K, Elguero J, Solimannejad M (2006) Theoretical study of dihydrogen bonds between $(\mathrm{XH}) 2, \mathrm{X}=\mathrm{Li}, \mathrm{Na}, \mathrm{BeH}$, and $\mathrm{MgH}$, and weak hydrogen bond donors $(\mathrm{HCN}$, HNC, and HCCH). J Phys Chem A 110:10279

23. Zabardasti A, Arabpour M (2012) Theoretical study of hydrogen and dihydrogen bond interaction of B6H10 with the HF molecule. Struct Chem 23:473-477

24. Zabardasti A, Arabpour M, Zare Nahid (2013) Theoretical study of hydrogen and dihydrogen bond interaction of B5H11 with the HF and LiH molecules. Comput Theor Chem 1008:27-31

25. Zabardasti A, Zare N, Arabpour M, Kakanejadifard A, Solimannejad M (2013) Theoretical study of mixed hydrogen and dihydrogen bond interactions in BH4(NH3)n - clusters. J Chem 1-7 26. Zabardasti A, Kakanejadifard A, Moosavi S, Bigleri Z, Solimannejad M (2010) Anticooperativity in dihydrogen bonded clusters of ammonia and BeH4 2-. J Mol Struc Theochem 945:97

27. Zabardasti A, Kakanejadifard A, Hoseini AS, Solimannejad M (2010) Competition between hydrogen and dihydrogen bonding: interaction of $\mathrm{B} 2 \mathrm{H} 6$ with $\mathrm{CH} 3 \mathrm{OH}$ and $\mathrm{CHnX} 3-\mathrm{nOH}$ derivatives. Dalton Trans 39:5918-5922

28. Zabardasti A, Joshaghani M, Solimannejad M (2010) Competition between hydrogen and dihydrogen bonding: interaction of B2H6 with HF and LiH. Bull Chem Soc Jpn 83:1359-1363

29. Zabardasti A, Kakanejadifard A, Zare N, Arabpor M (2011) Theoretical study of dihydrogen bonded clusters of water with tetrahydroborate. Struct Chem 22:691-695

30. Frisch MJ, Trucks GW, Schlegel HB, Scuseria GE, Robb MA, Cheeseman JR, Montgomery JA, Vreven T, Kudin KN, Burant JC, Millam JM, Iyengar SS, Tomasi J, Barone V, Mennucci B, Cossi M, Scalmani G, Rega N, Petersson GA, Nakatsuji H, Hada M, Ehara M, Toyota K, Fukuda R, Hasegawa J, Ishida M, Nakajima T, Honda Y, Kit ao O, Nakai H, Klene M, Knox JE, Hratchian HP, Cross JB, Adamo C, Jaramillo J, Gomperts R, Stratmann RE, Yazyev O, Austin AJ, Cammi R, Pomelli C, Ochterski JW, Ayala PY, Morokuma K, Voth GA, Salvador P,

Dannenberg JJ, Zakrzewski VG, Dapprich S, Daniels AD, Strain MC, Farkas O, Malick DK, Rabuck AD, Raghavachari K, Foresman JB, Ortiz JV, Cui Q, Baboul AG, Clifford S, Cioslowski J, Stefanov BB, Liu G, Liashenko A, Piskorz P, Komaromi I, Martin RL, Fox DJ, Keith T, AlLaham MA, Peng CY, Nanayakkara A, Challacombe M, Gill PMW, Johnson B, Chen

W, Wong MW, Gonzalez C, Pople JA (2003) GAUSSIAN 03. Gaussian Inc., Pittsburgh

31. Møller C, Plesset MS (1934) Note on an approximation treatment for many-electron systems. Phys Rev 46:618

32. Frisch MJ, Pople JA, Binkley JS (1984) Self-consistent molecular orbital methods 25. Supplementary functions for Gaussian basis sets. J Chem Phys 80:3265

33. Boys SF, Bernardi F (1970) The calculation of small molecular interactions by the differences of separate total energies. Some procedures with reduced errors. Mol Phys 19:553-566

34. Bader RFW (1990) Atoms in molecules: a quantum theory. Oxford University Press, Oxford 
35. Bader RFW (1991) A quantum theory of molecular structure and its applications. Chem Rev 91:893-928

36. Grabowski SJ, Ugalde JM (2010) Bond Paths Show Preferable Interactions: Ab initio and QTAIM Studies on the $\mathrm{X}-\mathrm{H} \_$_ $\mathrm{p}$ hydrogen bond. J Phys Chem A 114:7223-7229

37. Oliveira BG, Arau'jo RCMU, Leite ES, Ramos MN (2011) A

theoretical analysis of topography and molecular parameters of the $\mathrm{CFCl} 3$ _ $\mathrm{O} 3$ complex: linear and bifurcate halogen-oxygen bonding interactions. Int J Quantum Chem 111:111-116 38. Oliveira BG, Arau'jo RCMU, Silva JJ, Ramos MN (2010) A theoretical study of three and four proton donors on linear $\mathrm{HX}_{-} \mathrm{BeH}_{2} \_\mathrm{HX}$ and bifurcate $\mathrm{BeH} 2 \_2 \mathrm{HX}$ trimolecular dihydrogen- bonded complexes with $\mathrm{X}=\mathrm{CN}$ and NC. Struct Chem 21:221-228

39. Oliveira BG, Arau'jo RCMU, Ramos MN (2008) Multiple proton donors on $\mathrm{BeH} 2 \_2 \mathrm{HCl}$ trimolecular dihydrogen-bonded complex: some theoretical insights. Struct Chem 19:665-670 40. Oliveira BG, Arau'jo RCMU, Ramos MN (2008) The (H-d__ H+d) charge transfer and the evaluation of the harmonic molecular properties of dihydrogen-bonded complexes formed by $\mathrm{BeH} 2$ _ HX with X=F, Cl, CN, and CCH. Struct Chem 19:185-189 41. Capim SL, Santana SR, Oliveira BG, Rocha GB, Vasconcellos MLAA (2010) Revisiting the origin of the referential p-p stacking conformation of the (+)-8-phenylmenthyl acrylate. J Braz Chem Soc 21:1718-1726

42. Oliveira BG (2012) Interplay between dihydrogen and alkali- halogen bonds: Is there some covalency upon complexation of ternary systems+ Theor Comput Chem 998:173-182

43. Reed AE, Curtiss LA, Weinhold F (1988) Intermolecular interactions from a natural bond orbital, donor-acceptor viewpoint. Chem Rev 88:899-926 